\title{
In vivo postprandial lipid partitioning in liver and skeletal muscle in prediabetic and diabetic rats
}

\author{
R. A. M. Jonkers • L. J. C. van Loon • \\ K. Nicolay • J. J. Prompers
}

Received: 11 September 2012 / Accepted: 12 November 2012 /Published online: 13 December 2012

(C) The Author(s) 2012. This article is published with open access at Springerlink.com

\begin{abstract}
Aims/hypothesis Insulin resistance and type 2 diabetes have been associated with ectopic lipid deposition. This study investigates the derangements in postprandial lipid handling in liver and skeletal muscle tissue at different stages during the pathogenesis of type 2 diabetes in a rat model.

Methods Four groups $(n=6)$ of male Zucker diabetic fatty rats were used for this study: prediabetic falfa rats and healthy $f a /+$ littermates at the age of 6 weeks, and diabetic falfa rats and healthy $f a /+$ littermates at the age of 12 weeks. In vivo ${ }^{1} \mathrm{H}-\left[{ }^{13} \mathrm{C}\right]$ magnetic resonance spectroscopy measurements were performed in liver and tibialis anterior muscle at baseline and 4, 24 and $48 \mathrm{~h}$ after oral administration of $1.5 \mathrm{~g}$ $\left[\mathrm{U}_{-}{ }^{13} \mathrm{C}\right]$ algal lipid mixture per kilogram body weight. Total and ${ }^{13} \mathrm{C}$-labelled intracellular lipid contents were determined from the magnetic resonance spectra.

Results In both prediabetic and diabetic rats, total lipid contents in muscle and liver were substantially higher than in healthy controls and this was accompanied by a 2.3 -fold greater postprandial lipid uptake in the liver $(p<0.001)$. Interestingly, in prediabetic rats, skeletal muscle appeared to be protected from excess lipid uptake whereas after developing overt diabetes muscle lipid uptake was 3.4-fold higher than in controls $(p<0.05)$. Muscle lipid use was significantly lower in prediabetic and diabetic muscle, indicative of impairments in lipid oxidation.
\end{abstract}

R. A. M. Jonkers $\cdot$ K. Nicolay $\cdot$ J. J. Prompers $(\bowtie)$

Biomedical NMR, Department of Biomedical Engineering,

Eindhoven University of Technology, P.O. Box 513, 5600 MB,

Eindhoven, the Netherlands

e-mail: j.j.prompers@tue.nl

L. J. C. van Loon

NUTRIM School for Nutrition, Toxicology and Metabolism, Department of Human Movement Sciences, Maastricht University Medical Centre+, Maastricht, the Netherlands
Conclusions/interpretation In vivo postprandial lipid handling is disturbed in both liver and skeletal muscle tissue in prediabetic and diabetic rats, but the uptake of dietary lipids in muscle is only increased after the development of overt diabetes.

Keywords Carbon-13 - Insulin resistance ·

Intrahepatocellular lipids $\cdot$ Intramyocellular lipids $\cdot$ Lipid uptake $\cdot$ Magnetic resonance spectroscopy $\cdot$ Prediabetes . Type 2 diabetes $\cdot$ ZDF rat

$\begin{array}{ll}\text { Abbreviations } \\ \text { En\% } & \text { Energy per cent } \\ \text { FAT/CD36 } & \text { Fatty acid translocase CD36 } \\ \text { GC-C-IRMS } & \begin{array}{l}\text { Gas chromatography-combustion-isotope } \\ \text { ratio mass spectrometry }\end{array} \\ \text { ICL } & \text { Intracellular lipids } \\ \text { IHCL } & \text { Intrahepatocellular lipids } \\ \text { IMCL } & \text { Intramyocellular lipids } \\ \text { LASER } & \text { Localisation by adiabatic selective refocusing } \\ \text { MRS } & \text { Magnetic resonance spectroscopy } \\ \text { POCE } & \text { Proton-observed, carbon-edited } \\ \text { SWAMP } & \text { Sequence for water suppression with } \\ & \text { adiabatic modulated pulses } \\ \text { TA } & \text { Tibialis anterior } \\ \text { TAG } & \text { Triacylglycerol } \\ \text { ZDF } & \text { Zucker diabetic fatty }\end{array}$

\section{Introduction}

Insulin resistance and type 2 diabetes have been associated with excess lipid accumulation in non-adipose tissues such as skeletal muscle [1,2] and liver [3, 4]. The mechanistic link between intracellular lipid overload and insulin resistance is believed to reside in the accumulation of lipid-derived intermediates, such as diacylglycerols and 
ceramides, which trigger activation of novel protein kinase $\mathrm{C}$ isozymes leading to impairments in insulin signalling [5]. It remains unknown, however, whether the excess storage of lipids in insulin-resistant muscle and liver is a consequence of greater lipid uptake from the circulation, decreased lipid use through oxidation, release and/or secretion, or a combination of both.

Results from studies on intracellular lipid handling in insulin-resistant skeletal muscle and liver tissue are far from consistent. Lipid uptake in muscle of insulin-resistant and type 2 diabetic individuals and corresponding animal models has been reported to be either higher (mostly but not exclusively in postprandial conditions) [6-15], similar [16-20] or lower (mostly but not exclusively in postabsorptive conditions) $[9,21-28]$ when compared with insulinsensitive controls. Lipid oxidation in insulin-resistant or type 2 diabetic muscle has also been reported to be either lower $[9,17,18,20-25,29]$ or unchanged $[6,7,14,19]$ when compared with healthy controls. Data on lipid uptake in insulin-resistant and type 2 diabetic liver tissue are scarce and have predominantly been obtained from animal models, showing either an increase [12, 21, 30] or no significant difference [8, 20, 31] compared with controls. Liver lipid secretion, as measured by the production of VLDL particles, is generally reported to be greater in an insulin-resistant or type 2 diabetic state [32-34]. Differences in study design, such as the nutritional state (postprandial vs postabsorptive conditions), can only explain part of the discrepancy in the literature. In addition, other factors, such as the stage of type 2 diabetes pathogenesis and the methodology applied to assess lipid handling, are likely to contribute to the apparent inconsistency.

Recently, we introduced the application of ${ }^{1} \mathrm{H}-\left[{ }^{13} \mathrm{C}\right]$ magnetic resonance spectroscopy (MRS) in combination with the oral administration of ${ }^{13} \mathrm{C}$-labelled lipids to determine in vivo postprandial lipid partitioning in skeletal muscle and liver tissue in rodents [35]. ${ }^{1} \mathrm{H}-\left[{ }^{13} \mathrm{C}\right] \mathrm{MRS}$ indirectly detects the ${ }^{13} \mathrm{C}$-labelled lipids through the attached ${ }^{1} \mathrm{H}$ nuclei. After correction for the natural abundance of ${ }^{13} \mathrm{C}$, this allows the amount of lipids stored in the tissue originating from the dietary ${ }^{13} \mathrm{C}$-labelled lipids to be quantified. MRS is noninvasive and does not involve harmful radiation, allowing repeated measurements to follow the time course of uptake and depletion of ${ }^{13} \mathrm{C}$-labelled lipids in multiple tissues. We have shown that in healthy rats the uptake of ${ }^{13} \mathrm{C}$-labelled lipids was about tenfold higher in liver than in skeletal muscle [35].

In this study we applied the ${ }^{1} \mathrm{H}-\left[{ }^{13} \mathrm{C}\right]$ MRS technique in prediabetic and diabetic rat models with the aim of gaining greater insight into the derangements in liver and skeletal muscle lipid handling at different stages during the pathogenesis of type 2 diabetes. Total and ${ }^{13} \mathrm{C}$-labelled lipid concentrations were measured in liver and skeletal muscle tissue at baseline, and at 4,24 and $48 \mathrm{~h}$ after the oral administration of $\left[\mathrm{U}^{13} \mathrm{C}\right]$ algal lipid mixture. Based on previous observations, we hypothesised that postprandial lipid handling is disturbed in both liver and skeletal muscle tissue of prediabetic rats, and that these disturbances are further exacerbated following the development of overt type 2 diabetes.

\section{Methods}

Animals and study design Four groups $(n=6)$ of male Zucker diabetic fatty (ZDF) rats (Charles River Laboratories, Sulzfield, Germany) were used for this study: (1) obese, prediabetic fa/fa rats at the age of 6 weeks; (2) lean, healthy $f a /+$ littermates at the age of 6 weeks; (3) obese, diabetic $f a / f a$ rats at the age of 12 weeks and (4) lean, healthy $f a /+$ littermates at the age of 12 weeks $[36,37]$. The rats were housed in pairs at $20^{\circ} \mathrm{C}$ and $50 \%$ humidity, on a $12 \mathrm{~h}$ light-dark cycle with free access to Purina 5008 diet (19 energy per cent [En\%] from fat, $54 \mathrm{En} \%$ from carbohydrates and $27 \mathrm{En} \%$ from protein; SM R/M modified 5008 diet; Ssniff Spezialdiäten, Soest, Germany) and water during the entire period of the experiment. All experimental procedures were reviewed and approved by the local institutional animal care committee (Maastricht University, Maastricht, the Netherlands).

Before the administration of ${ }^{13} \mathrm{C}$-labelled lipids, ${ }^{1} \mathrm{H}-\left[{ }^{13} \mathrm{C}\right]$ MRS measurements were carried out on all rats to determine total $\left({ }^{12} \mathrm{C}+{ }^{13} \mathrm{C}\right)$ and ${ }^{13} \mathrm{C}$-enriched intracellular lipid (ICL) concentrations in the tibialis anterior (TA) muscle (intramyocellular lipids, IMCL) and liver (intrahepatocellular lipids, IHCL) at baseline. Two days later, rats were orally administered $1.5 \mathrm{~g}\left[\mathrm{U}_{-}{ }^{13} \mathrm{C}\right]$ algal lipid mixture $\left({ }^{13} \mathrm{C}\right.$ enrichment $>98 \%$; fatty acid composition: $53 \%$ palmitic acid, $9 \%$ palmitoleic acid, 28\% oleic acid, and 6\% linoleic acid; Cambridge Isotope Laboratories, Andover, MA, USA) per kg body weight. ${ }^{1} \mathrm{H}-\left[{ }^{13} \mathrm{C}\right]$ MRS measurements were performed at 4, 24 and $48 \mathrm{~h}$ after administration of ${ }^{13} \mathrm{C}$-labelled lipids.

Blood samples were taken from the vena saphena after each MRS experiment and were used for the determination of plasma glucose, NEFA and triacylglycerol (TAG) concentrations.

MRS experiments During the MRS experiments, rats were anaesthetised using 1.5-2.5\% isoflurane (IsoFlo; Abbott Laboratories, Maidenhead, UK). Body temperature was maintained at $37 \pm 1^{\circ} \mathrm{C}$ using heating pads. All MRS experiments were performed on a $6.3 \mathrm{~T}$ horizontal Bruker MR system (Bruker, Ettlingen, Germany). In each rat, localised ${ }^{1} \mathrm{H}-\left[{ }^{13} \mathrm{C}\right]$ MRS was performed first on a $3.5 \times 3.5 \times 3.5 \mathrm{~mm}^{3}$ (in $f a /+$ rats) or $3 \times 3 \times 3 \mathrm{~mm}^{3}$ (in $f a / f a$ rats) voxel placed in 
the TA muscle (Fig. 1a,b) and, after repositioning, on a $4 \times$ $2 \times 4 \mathrm{~mm}^{3}$ voxel in the median lobe of the liver (Fig. 1c,d) using the LASER-POCE method as described previously [35]. For each voxel, 64 water-suppressed LASER-POCE experiments, consisting of 16 averages each, were performed serially in an interleaved fashion with the ${ }^{13} \mathrm{C}$-editing pulse turned on every other experiment. An unsuppressed water spectrum, consisting of 16 averages, was recorded from the same voxel and was used as internal reference.

MRS data analysis Spectra from the 32 LASER-POCE experiments with and without ${ }^{13} \mathrm{C}$ editing were added separately and the difference spectrum was calculated using Matlab (R2009b; Mathworks, Natick, MA, USA). Water and ICL methylene (ICL-CH $\mathrm{CH}_{2}$ signal at $1.3 \mathrm{ppm}$ ) peak areas were quantified from the unsuppressed and suppressed spectra, respectively, using the jMRUI software package [38] as described previously [39]. Total $\left({ }^{12} \mathrm{C}+{ }^{13} \mathrm{C}\right)$ and ${ }^{13} \mathrm{C}$-labelled ICL levels were determined from the LASER-POCE spectra without ${ }^{13} \mathrm{C}$ editing and the difference spectra, respectively, and are presented as a percentage of the unsuppressed water signal measured in the same voxel. The average relative ${ }^{13} \mathrm{C}$ enrichment determined at baseline was used to correct the ${ }^{13} \mathrm{C}$-labelled ICL levels at 4,24 and $48 \mathrm{~h}$ after ${ }^{13} \mathrm{C}$-labelled lipid administration for natural abundance of ${ }^{13} \mathrm{C}$. Previously, we have shown that the in-vivo ${ }^{1} \mathrm{H}-\left[{ }^{13} \mathrm{C}\right]$ MRS determination of ${ }^{13} \mathrm{C}$ enrichment of IHCL was in agreement with the ex-vivo analysis by gas chromatographycombustion-isotope ratio mass spectrometry (GC-C-IRMS) and that the $1.1 \%$ natural abundance of ${ }^{13} \mathrm{C}$ could be reliably determined in both IMCL and IHCL pools [35].
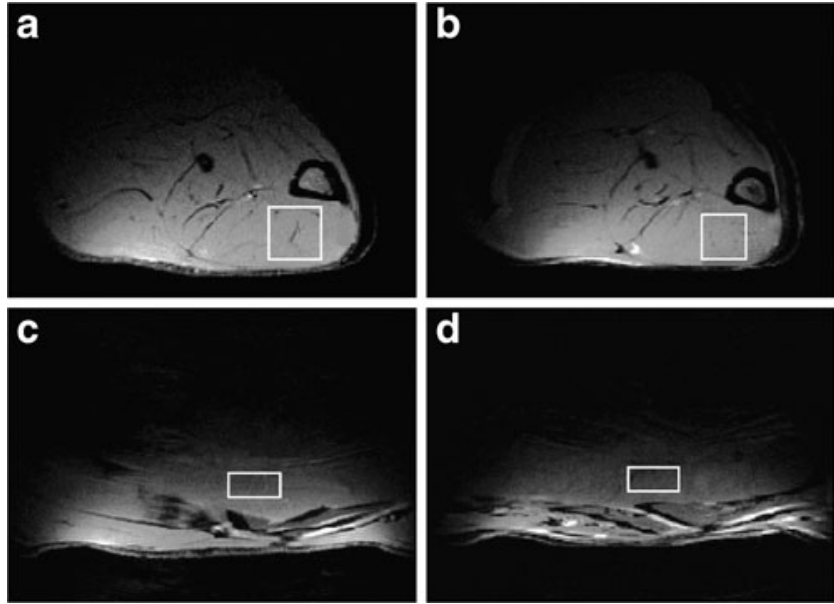

Fig. $1 T_{1}$-weighted transversal images of a $f a /+$ rat left hindlimb with a $3.5 \times 3.5 \times 3.5 \mathrm{~mm}^{3}$ voxel in the TA muscle (a), a falfa rat left hindlimb with a $3 \times 3 \times 3 \mathrm{~mm}^{3}$ voxel in the TA muscle (b), a $\mathrm{fa} /+$ rat abdomen with a $4 \times 2 \times 4 \mathrm{~mm}^{3}$ voxel in the median lobe of the liver (c) and a falfa rat abdomen with a $4 \times 2 \times 4 \mathrm{~mm}^{3}$ voxel in the median lobe of the liver (d)
Plasma analysis Blood samples were collected in K-EDTAcoated tubes at baseline and at 4, 24 and $48 \mathrm{~h}$ after ${ }^{13} \mathrm{C}$-labelled lipid administration, centrifuged for $10 \mathrm{~min}$ at $1,000 \mathrm{~g}$, and portioned plasma volumes were frozen in liquid nitrogen and stored at $-80^{\circ} \mathrm{C}$. Concentrations of plasma glucose, NEFA and TAG were determined using an automatic glucometer (FreeStyle; Abbott, Abbott Park, IL, USA), the NEFA-HR(2) kit (Wako Chemicals, Neuss, Germany) and the serum TAG determination kit (Sigma-Aldrich, Zwijndrecht, the Netherlands), respectively.

Statistics All data ( $n=6$ per group) are expressed as means \pm SEM. Data were analysed using mixed-model repeatedmeasures ANOVA with time point (baseline and 4, 24 and $48 \mathrm{~h}$ post) as the within-subject factor, and age (6 and 12 weeks) and genotype ( $f a /+$ and $f a / f a)$ as betweensubject factors. Only if the interaction term between the factors was found to be significant, the effect of each factor was analysed separately using one-way ANOVA (time point) or unpaired Student's $t$ tests (age and genotype). Bonferroni corrections were applied when appropriate. Statistical analyses were performed using the IBM SPSS statistics software package (SPSS, version 19, Chicago, IL, USA). The level of significance was set at $p<0.05$.

\section{Results}

Body weight The body weight of $f a / f a$ rats was $18 \%$ higher than that of $f a /+$ rats $(p<0.001)$, independent of age (Table 1). Rats at 12 weeks of age were $95 \%$ heavier than rats at 6 weeks of age $(p<0.001)$, independent of genotype. The amount of ${ }^{13} \mathrm{C}$-labelled lipids that was administered to the rats was scaled to body weight (Table 1).

Plasma glucose, NEFA and TAG Results of the plasma analyses are shown in Table 2. Plasma glucose concentrations were higher in $f a / f a$ rats compared with $f a /+$ rats independent of time point both at $6(12.2 \pm 0.7$ vs $7.3 \pm 0.3 \mathrm{mmol} / \mathrm{l}$, $p<0.001)$ and $12(18.9 \pm 0.8$ vs $6.9 \pm 0.3 \mathrm{mmol} / 1, p<0.001)$ weeks of age. In diabetic $f a / f a$ rats at 12 weeks of age, plasma glucose was $50 \%$ higher when compared with the prediabetic $f a / f a$ rats at 6 weeks of age independent of time point $(p<0.01)$. The administration of ${ }^{13} \mathrm{C}$-labelled lipids did not affect plasma glucose levels after 4, 24 and $48 \mathrm{~h}$ in any group $(p=0.296)$. At 6 weeks of age, plasma NEFA concentrations did not differ between prediabetic $f a / f a$ rats and their control littermates $(p=0.820)$. In contrast, at 12 weeks of age, plasma NEFA concentrations in diabetic $f a / f a$ rats were $86 \%$ higher than in $f a /+$ rats independent of time point $(p<0.05)$. Plasma NEFA at 4 and $24 \mathrm{~h}$ after the administration of ${ }^{13} \mathrm{C}$-labelled lipids was not significantly different from baseline, but at $48 \mathrm{~h}$ after ${ }^{13} \mathrm{C}$-labelled lipid administration it had decreased by as 
Table 1 Body weight of rats and amount of ${ }^{13} \mathrm{C}$-labelled lipid mixture administered

\begin{tabular}{|c|c|c|c|c|}
\hline \multirow[t]{2}{*}{ Body weight/amount of lipid administered } & \multicolumn{2}{|l|}{6 weeks } & \multicolumn{2}{|l|}{12 weeks } \\
\hline & $f a /+$ & $f a / f a$ & $f a /+$ & $f a / f a$ \\
\hline Body weight (g) & $166 \pm 7$ & $190 \pm 12 * * *$ & $319 \pm 10^{\dagger \dagger \dagger}$ & $374 \pm 11 * * *, \dagger \dagger$ \\
\hline${ }^{13} \mathrm{C}$-labelled algal lipid mixture (mg) & $247 \pm 26$ & $286 \pm 43 * * *$ & $478 \pm 15^{\dagger \dagger \dagger}$ & $563 \pm 17 * * *, \dagger \dagger$ \\
\hline
\end{tabular}

Data are means \pm SEM

$* * * p<0.001$, compared with $f a /+;{ }^{\dagger \dagger} p<0.001$, compared with 6 weeks

much as $60 \pm 6 \%$ when compared with the earlier time points in all groups. Plasma TAG concentrations were higher in $\mathrm{fa} / \mathrm{fa}$ rats compared with $f a /+$ rats, independent of age and time point $(1.64 \pm 0.10$ vs $0.43 \pm 0.02 \mathrm{mmol} / 1, p<0.001)$. The administration of ${ }^{13} \mathrm{C}$-labelled lipids did not affect plasma TAG levels after 4, 24 and $48 \mathrm{~h}$ in any group.

MRS data Figure 2 displays typical examples of watersuppressed LASER-POCE spectra acquired from TA muscle and liver at $4 \mathrm{~h}$ after the administration of ${ }^{13} \mathrm{C}$-labelled lipids in a healthy $f a /+$ rat and a diabetic $f a / f a$ rat at 12 weeks of age. The lipid methylene signal at $1.30 \mathrm{ppm}$ in the normal ${ }^{1} \mathrm{H}$ spectra without the ${ }^{13} \mathrm{C}$-editing pulse was used for quantification of total $\left({ }^{12} \mathrm{C}+{ }^{13} \mathrm{C}\right)$ IMCL and IHCL. The difference spectra, resulting from the subtraction of the experiments with and without the ${ }^{13} \mathrm{C}$-editing pulse, only contain signals from ${ }^{1} \mathrm{H}-{ }^{13} \mathrm{C}$ coupled resonances and were used to determine the ${ }^{13} \mathrm{C}$ enrichment of the IMCL and IHCL pools.

Total IMCL and IHCL concentrations at baseline and 4, 24 and $48 \mathrm{~h}$ after oral administration of the $\left[\mathrm{U}-{ }^{13} \mathrm{C}\right]$ algal lipid mixture in $f a /+$ and $f a / f a$ rats at 6 and 12 weeks of age are shown in Fig. 3. Data are expressed as percentage of the unsuppressed water signal measured in the same voxel. At both ages, total IMCL and IHCL content were higher in $f a / f a$ rats compared with $f a /+$ rats. In $f a / f a$ rats, IMCL content was $73 \%$ higher at 12 weeks compared with 6 weeks $(p<0.001)$, whereas in $f a /+$ rats IMCL was $43 \%$ lower at 12 weeks than at 6 weeks $(p<0.001)$. IHCL content was $48 \%$ higher at 12 weeks of age compared with 6 weeks, independent of genotype $(p<0.05)$. The administration of ${ }^{13} \mathrm{C}$-labelled lipids did not affect total IMCL and IHCL levels, except for a very slight decrease in IMCL in all groups at $48 \mathrm{~h}$ after administration, which is probably related to the decrease in plasma NEFA concentration at this time point.

The relative ${ }^{13} \mathrm{C}$ enrichments of IMCL and IHCL measured at baseline were $1.19 \pm 0.04 \%$ and $1.39 \pm 0.06 \%$, respectively, both independent of genotype and age. These values were used to correct ${ }^{13} \mathrm{C}$-labelled IMCL and IHCL levels at 4,24 and $48 \mathrm{~h}$ after the administration of ${ }^{13} \mathrm{C}$-labelled lipids for natural abundance of ${ }^{13} \mathrm{C}$ and the results are shown in Fig. 4. Thus, ${ }^{13} \mathrm{C}$-enriched IMCL and
Table 2 Plasma glucose, NEFA and TAG concentrations at baseline and 4, 24 and $48 \mathrm{~h}$ after oral administration of the ${ }^{13} \mathrm{C}$-labelled lipid mixture to rats

Data are means \pm SEM

${ }^{*} p<0.05, * * * p<0.001$ compared with $f a /+;{ }^{\dagger \dagger} p<0.01$, compared with 6 weeks; $+4 t p<0.001$, compared with baseline; ${ }^{\S} p<0.05$, compared with $4 \mathrm{~h}$ post lipid administration; ${ }^{\top} p<0.05$, compared with $24 \mathrm{~h}$ post lipid administration

\begin{tabular}{|c|c|c|c|c|}
\hline \multirow[t]{2}{*}{ Variable } & \multicolumn{2}{|l|}{6 weeks } & \multicolumn{2}{|l|}{12 weeks } \\
\hline & $f a /+$ & falfa & $f a /+$ & $f a l f a$ \\
\hline \multicolumn{5}{|c|}{ Plasma glucose $(\mathrm{mmol} / \mathrm{l})$} \\
\hline Baseline & $7.0 \pm 0.3$ & $11.8 \pm 1.3 * * *$ & $7.5 \pm 0.3$ & $17.7 \pm 1.7 * * *, \dagger \dagger$ \\
\hline $4 \mathrm{~h}$ post & $7.2 \pm 0.4$ & $11.0 \pm 0.9 * * *$ & $6.5 \pm 0.7$ & $18.9 \pm 2.2 * * *, \dagger \dagger$ \\
\hline $24 \mathrm{~h}$ post & $6.9 \pm 0.1$ & $13.5 \pm 0.8^{* * *}$ & $7.0 \pm 0.2$ & $20.7 \pm 0.3 * * *, \dagger \dagger$ \\
\hline $48 \mathrm{~h}$ post & $8.1 \pm 1.2$ & $12.6 \pm 2.2 * * *$ & $6.5 \pm 0.7$ & $18.4 \pm 1.3^{* * *, \dagger \dagger}$ \\
\hline \multicolumn{5}{|c|}{ Plasma NEFA (mmol/1) } \\
\hline Baseline & $0.32 \pm 0.03$ & $0.38 \pm 0.06$ & $0.24 \pm 0.04$ & $0.44 \pm 0.04 *$ \\
\hline $4 \mathrm{~h}$ post & $0.28 \pm 0.04$ & $0.29 \pm 0.04$ & $0.22 \pm 0.06$ & $0.50 \pm 0.09 *$ \\
\hline $24 \mathrm{~h}$ post & $0.35 \pm 0.05$ & $0.26 \pm 0.05$ & $0.27 \pm 0.07$ & $0.34 \pm 0.05 *$ \\
\hline $48 \mathrm{~h}$ post & $0.15 \pm 0.05^{\text {t+t, }, \text {, }}$ & $0.13 \pm 0.02^{\dagger+\ddagger, \S}$ & $0.08 \pm 0.02^{+1 \neq, \S, \pi}$ & $0.26 \pm 0.08^{*},+ \pm \neq, \S$ \\
\hline \multicolumn{5}{|c|}{ Plasma TAG (mmol/l) } \\
\hline Baseline & $0.47 \pm 0.05$ & $1.54 \pm 0.30^{* * *}$ & $0.45 \pm 0.02$ & $1.52 \pm 0.20 * * *$ \\
\hline $4 \mathrm{~h}$ post & $0.40 \pm 0.03$ & $1.66 \pm 0.34 * * *$ & $0.52 \pm 0.05$ & $1.51 \pm 0.23 * * *$ \\
\hline $24 \mathrm{~h}$ post & $0.33 \pm 0.05$ & $1.28 \pm 0.18^{* * *}$ & $0.36 \pm 0.05$ & $1.39 \pm 0.09^{* * *}$ \\
\hline $48 \mathrm{~h}$ post & $0.42 \pm 0.05$ & $1.97 \pm 0.31 * * *$ & $0.47 \pm 0.06$ & $2.16 \pm 0.34 * * *$ \\
\hline
\end{tabular}



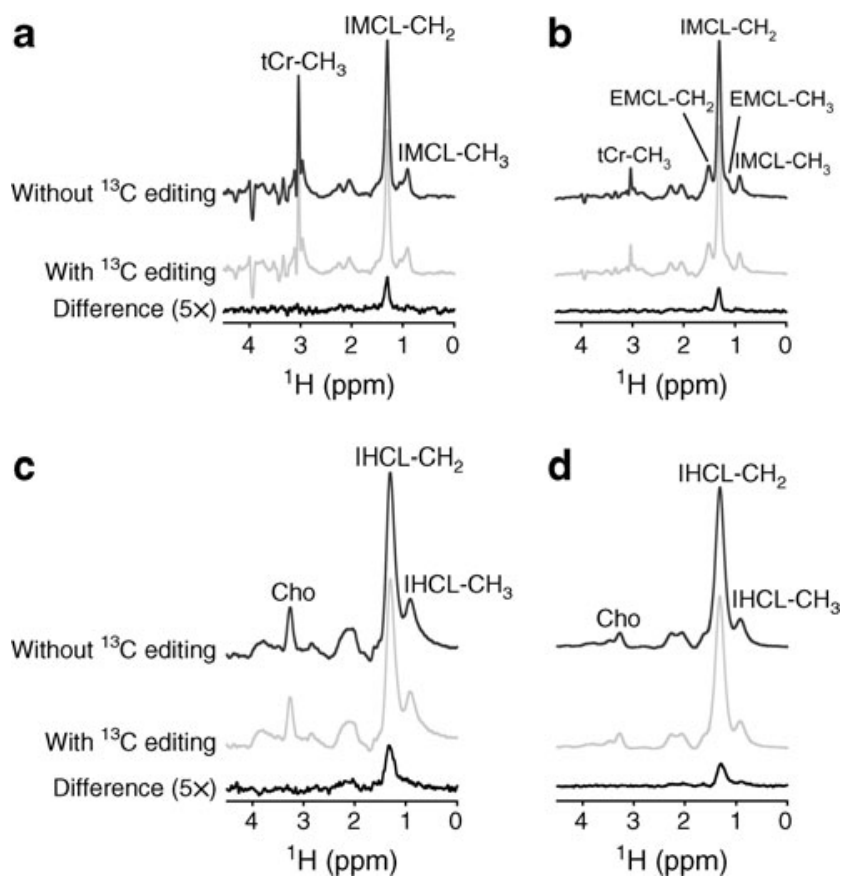

Fig. 2 Typical examples of LASER-POCE spectra from TA muscle (a, b) and liver (c, d) from a healthy $f a /+$ rat $(\mathbf{a}, \mathbf{c})$ and a diabetic $f a / f a$ rat (b, d) at 12 weeks of age. Spectra were acquired $4 \mathrm{~h}$ after the oral administration of $1.5 \mathrm{~g}\left[\mathrm{U}-{ }^{13} \mathrm{C}\right]$ algal lipid mixture per $\mathrm{kg}$ body weight. LASER-POCE spectra without ${ }^{13} \mathrm{C}$ editing, with ${ }^{13} \mathrm{C}$ editing and the calculated difference spectra containing only ${ }^{13} \mathrm{C}$-coupled ${ }^{1} \mathrm{H}$ resonances $(5 \times$ magnification) are shown. Peak annotations: $\mathrm{tCr}$, total creatine; EMCL, extramyocellular lipids; Cho, choline

IHCL concentrations in Fig. 4 represent the amount of lipids stored in muscle and liver originating from the administered ${ }^{13}$ C-labelled lipids.

At 6 weeks of age, ${ }^{13} \mathrm{C}$-labelled IMCL content at $4 \mathrm{~h}$ after administration of ${ }^{13} \mathrm{C}$-labelled lipids was $31 \%$ lower in $\mathrm{fa} / \mathrm{fa}$ rats than in $f a /+$ rats $(p<0.05)$, indicating a lower postprandial muscle lipid uptake in prediabetic rats compared with controls (Fig. 4a). In $f a /+$ rats at 12 weeks of age, ${ }^{13} \mathrm{C}$-labelled IMCL content $4 \mathrm{~h}$ post lipid administration was $44 \%$ lower compared with the content in $f a /+$ rats at 6 weeks $(p<0.05)$, implying that in control rats muscle lipid uptake decreased with ageing (Fig. 4a,b). In contrast, in diabetic $f a / f a$ rats at 12 weeks of age, ${ }^{13} \mathrm{C}$-labelled IMCL at $4 \mathrm{~h}$ post lipid administration was $217 \%$ higher compared with prediabetic $f a / f a$ rats at 6 weeks $(p<0.01)$, resulting in a $243 \%$ higher ${ }^{13} \mathrm{C}$ enrichment of IMCL at $4 \mathrm{~h}$ in comparison with $\mathrm{fa} /+$ controls of the same age $(p<0.05)$ (Fig. 4a,b). In all groups, the ${ }^{13} \mathrm{C}$ enrichment of IMCL decreased as a function of time between 4 and $48 \mathrm{~h}$ after administration. However, in contrast to control $\mathrm{fa} /+$ rats, ${ }^{13} \mathrm{C}$-labelled IMCL in $\mathrm{fa} / \mathrm{fa}$ rats at both ages only started to decline at $48 \mathrm{~h}$ post lipid administration and did not significantly decrease between 4 and $24 \mathrm{~h}$, indicating a prolonged uptake or a decreased turnover of the ${ }^{13} \mathrm{C}$-labelled lipids in prediabetic and diabetic muscle (Fig. 4a,b).
At $4 \mathrm{~h}$ after the oral administration of ${ }^{13} \mathrm{C}$-labelled lipids, the ${ }^{13} \mathrm{C}$ enrichment of IHCL was 2.3-fold greater in falfa rats compared with $f a /+$ rats $(p<0.001)$, independent of age, implying that postprandial liver lipid uptake was greater in both prediabetic and diabetic rats compared with controls (Fig. 4c,d). At 12 weeks of age, ${ }^{13} \mathrm{C}$-labelled IHCL content was $\sim 50 \%$ higher compared with the content at 6 weeks of age $(p<0.05)$, independent of genotype and time point (Fig. $4 c, d$ ). In all groups, the ${ }^{13} \mathrm{C}$ enrichment of IHCL at 24 and $48 \mathrm{~h}$ was lower than at $4 \mathrm{~h}$ after the administration of ${ }^{13} \mathrm{C}$-labelled lipids $(p<0.001)$, but it was always higher in $f a / f a$ rats than in $f a /+$ rats $(p<0.001)$ (Fig. $4 c, d)$.

\section{Discussion}

This study aimed to clarify whether intracellular lipid accumulation in insulin-resistant and diabetic liver and skeletal muscle tissue is a consequence of increased lipid uptake, decreased lipid use, or a combination of both. Using noninvasive ${ }^{1} \mathrm{H}-\left[{ }^{13} \mathrm{C}\right] \mathrm{MRS}$ combined with the oral administration of a ${ }^{13} \mathrm{C}$-labelled lipid mixture [35], we showed that in vivo postprandial lipid uptake in liver in both prediabetic and diabetic rats was greater than the uptake in healthy, insulin-sensitive controls, while liver lipid use was not affected. Whereas skeletal muscle appeared to be protected from excess lipid uptake in the prediabetic state, muscle lipid uptake was massively increased following the development of overt type 2 diabetes. Skeletal muscle lipid turnover was significantly reduced in prediabetic and diabetic rats.

In this study, we used the ZDF rat as an animal model of type 2 diabetes. We, as well as others, have previously shown that $f a / f a$ ZDF rats progress from prediabetes to overt type 2 diabetes in a highly predictable age-dependent fashion $[37,40]$. At the age of 6 weeks, $f a / f a$ rats are in an insulin-resistant, prediabetic state characterised by normal plasma glucose levels in fasting conditions, slightly increased plasma glucose levels in the fed state, normal plasma NEFA but elevated plasma insulin and TAG levels [37, $40]$, which was confirmed in the present study. Between 8 and 10 weeks of age, $f a / f a$ rats progress from a normoglycaemic-hyperinsulinaemic to a hyperglycaemic-hyperinsulinaemic state $[37,40]$. In this study, we confirmed that the $f a / f a$ rats at 12 weeks of age developed overt type 2 diabetes. Heterozygous $\mathrm{fa} /+$ rats remained normoglycaemic and normoinsulinaemic and served as healthy controls [37, 40].

In liver of prediabetic and diabetic $f a / f a$ rats, the lipid content was 5.6-fold greater when compared with the healthy controls and this was accompanied by a 2.3 -fold greater dietary lipid uptake in the liver $4 \mathrm{~h}$ after lipid administration. These data are in accordance with previous observations of elevated lipid uptake in insulin-resistant 

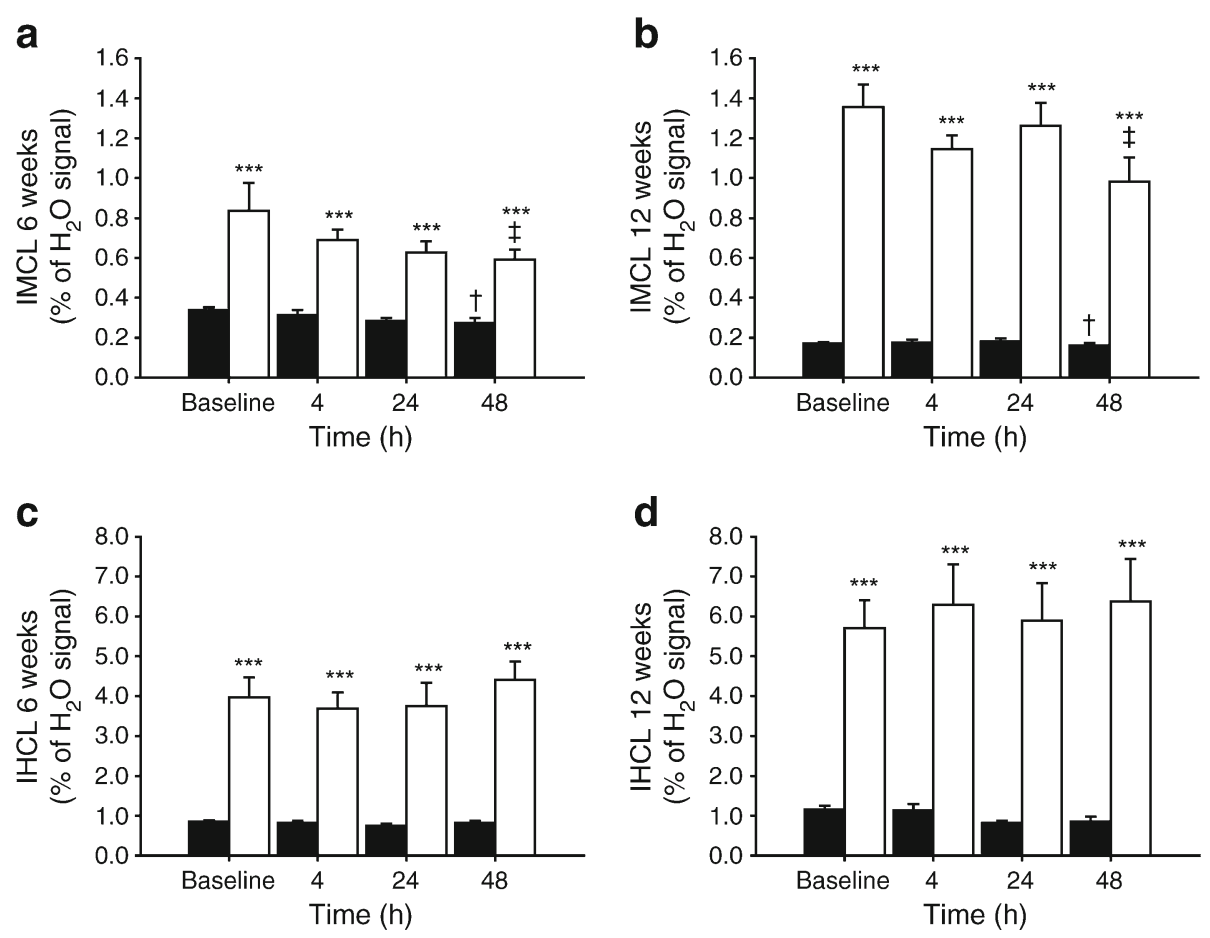

Fig. 3 Total $\left({ }^{12} \mathrm{C}+{ }^{13} \mathrm{C}\right)$ intracellular lipid content in TA muscle (IMCL; a, b) and liver (IHCL; c, d) of $f a /+$ rats (black bars) and $f a / f a$ rats (white bars) at $6(\mathbf{a}, \mathbf{c})$ and $12(\mathbf{b}, \mathbf{d})$ weeks of age measured at baseline and at 4, 24 and $48 \mathrm{~h}$ after the oral administration of $\left[\mathrm{U}_{-}{ }^{13} \mathrm{C}\right]$ algal lipid mixture ( $n=6$ per group). Data are expressed as a mean percentage of the unsuppressed water signal \pm SEM. IMCL content in

$f a /+$ rats and $f a / f a$ rats at 12 weeks was significantly different from 6 weeks, independent of time point $(p<0.05)$. IHCL content was significantly higher at 12 weeks than at 6 weeks, independent of genotype and time point $(p<0.05) .{ }^{* *} p<0.001$, compared with $f a /+$ rats; ${ }^{\dagger} p<0.05$, compared with baseline; ${ }^{\star} p<0.05$, compared with $24 \mathrm{~h}$ post lipid administration

and diabetic liver $[8,12,20,21,30]$. During periods of high lipid influx, such as during the immediate postprandial period, the liver acts as a systemic lipid buffer by taking up NEFA from the spillover pathway and chylomicron remnants, which are later re-secreted back into the circulation as VLDL [41, 42]. It has been suggested that in the insulin-resistant state, a greater proportion of meal derived fatty acids may be handled by the liver in the postprandial period [42], which is consistent with our data of increased hepatic lipid uptake in prediabetic and diabetic rats. Relative decreases in ${ }^{13} \mathrm{C}$-labelled IHCL content between 4 and $48 \mathrm{~h}$ after administration of ${ }^{13} \mathrm{C}$-labelled lipids were similar for all groups, indicating that liver lipid turnover was largely unaffected in prediabetic and diabetic rats when compared with the healthy controls.

Between 6 and 12 weeks of age, liver lipid content increased in both $f a / f a$ and $f a /+$ rats by $48 \%$, which was accompanied by a $62 \%$ higher uptake of dietary lipids in the liver, also independent of genotype. These increases in liver lipid content and uptake can therefore be ascribed to a general effect of ageing and are not necessarily specific for the transition from prediabetes to overt type 2 diabetes in $f a /$ $f a$ rats. In addition, the greater liver lipid uptake at 12 weeks could be due to the twofold higher amount of ${ }^{13} \mathrm{C}$-labelled

lipids that was administered to the rats at 12 weeks compared with rats at 6 weeks of age. However, at $4 \mathrm{~h}$ after intake of the ${ }^{13} \mathrm{C}$-labelled lipids, the relative increase in liver lipid uptake in $f a /+$ rats between 12 and 6 weeks of age was much larger than in falfa rats. This might indicate that in diabetic rats the maximum lipid buffer capacity of the liver is reached during the early postprandial period $(<4 \mathrm{~h})$, exposing other tissues, such as skeletal muscle, to increased plasma TAG and NEFA fluxes.

In addition to the steatotic liver, prediabetic $f a / f a$ rats also had 2.3-fold higher intracellular lipid levels in skeletal muscle when compared with the healthy controls. However, the greater IMCL content in prediabetic rats was not associated with excess postprandial muscle lipid uptake. In contrast to the highly elevated postprandial lipid uptake in liver, the uptake of dietary lipids in muscle at $4 \mathrm{~h}$ after intake was $31 \%$ lower in prediabetic rats when compared with the healthy controls. This result is in quantitative agreement with data from previous studies in insulin-resistant obese Zucker rats using orally administered ${ }^{14} \mathrm{C}$-labelled lipids $[20,21]$. However, in contrast to these reports and our own data, other studies have shown an increased postprandial muscle lipid uptake in insulin-resistant individuals and animals $[8,11,15]$. In addition, in vitro measurements in 

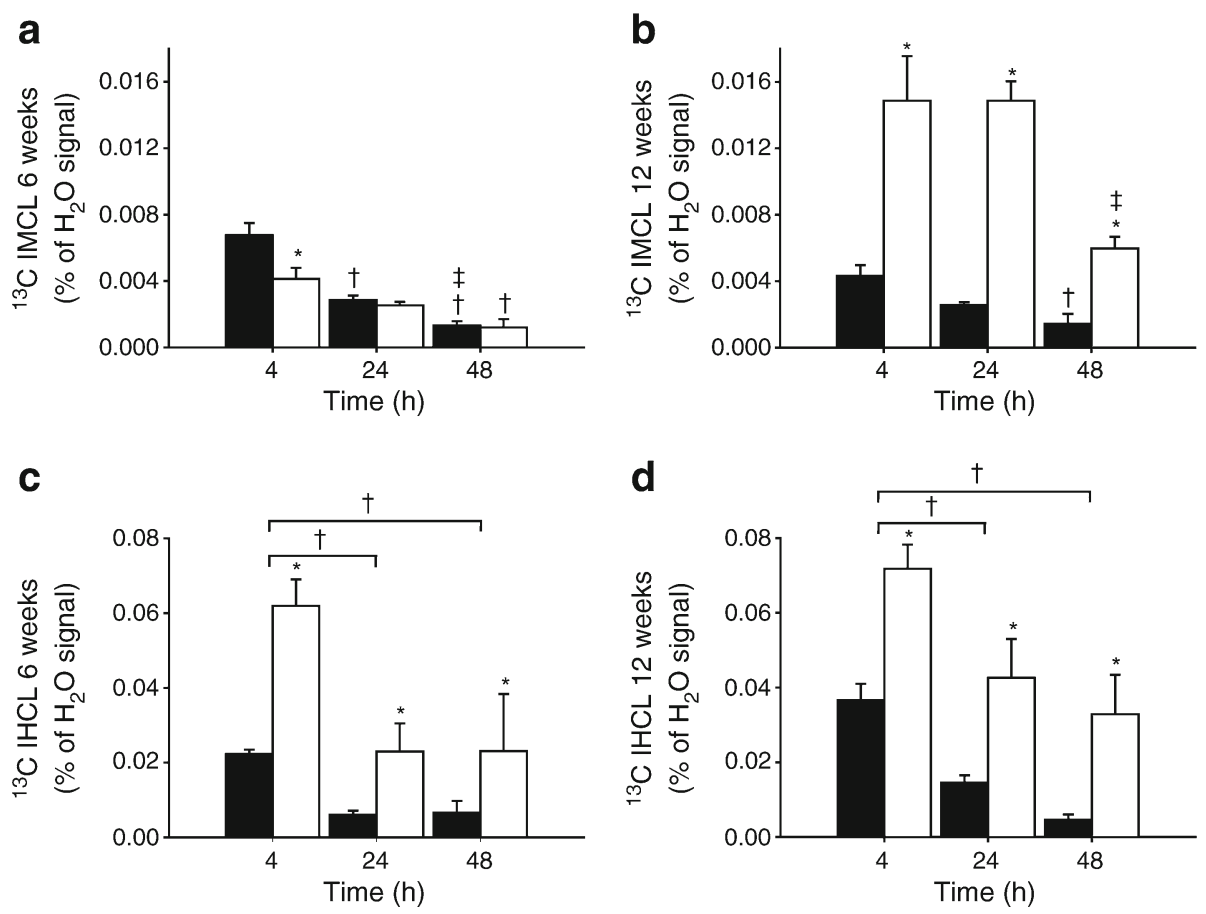

Fig. $4{ }^{13} \mathrm{C}$-enriched intracellular lipid content in TA muscle (IMCL; a, b) and liver (IHCL; c, d) of $f a /+$ rats (black bars) and $f a / f a$ rats (white bars) at $6(\mathbf{a}, \mathbf{c})$ and $12(\mathbf{b}, \mathbf{d})$ weeks of age determined at 4,24 and $48 \mathrm{~h}$ after the oral administration of $\left[\mathrm{U}^{13} \mathrm{C}\right]$ algal lipid mixture $(n=6$ per group). Data are expressed as a mean percentage of the unsuppressed water signal \pm SEM. ${ }^{13} \mathrm{C}$-enriched IMCL content in $f a /+$ rats at $4 \mathrm{~h}$ was significantly lower at 12 weeks than at 6 weeks $(p<0.05)$,

isolated muscle preparations and giant sarcolemmal vesicles yielded increased lipid uptake rates in muscle from insulinresistant obese individuals and obese Zucker rats [7, 10, 13, 14]. Whereas fatty acid concentrations in these in vitro experiments were identical for insulin-resistant and control muscle, muscle of prediabetic rats in our in-vivo studies was exposed to fourfold higher plasma TAG levels compared with controls. The amount of ${ }^{13} \mathrm{C}$-labelled lipids that was administered to the rats was scaled to body weight, but was only 1.2-fold higher in prediabetic rats than in controls. Therefore, the ${ }^{13} \mathrm{C}$-labelled lipids are likely to be more diluted in the plasma of prediabetic rats compared with controls, which might have resulted in an underestimation of the in vivo muscle lipid uptake in prediabetic rats. Unfortunately, we lack information about the ${ }^{13} \mathrm{C}$ enrichment of plasma TAG, because it was not possible to extract the lipid fraction from the small blood samples obtainable from rats, which is required for GC-C-IRMS. The lower lipid uptake in muscle of prediabetic rats as observed in the current study suggests that, after the initial buffering by the liver, more of the dietary lipids are shunted toward adipose tissue storage. Previous studies have indeed shown that upregulation of adipocyte lipid uptake is an early event in ZDF rats [31] and that in obese Zucker rats the majority of dietary lipids are directed toward storage in adipose tissue [20,21].

whereas in $f a / f a$ rats ${ }^{13} \mathrm{C}$-enriched IMCL content was significantly higher at 12 weeks than at 6 weeks for each time point $(p<0.05)$.

${ }^{13} \mathrm{C}$-enriched IHCL content was significantly higher at 12 weeks than at 6 weeks, independent of genotype and time point $(p<0.05)$. ${ }^{*} p<0.05$, compared with $f a /+$ rats; ${ }^{\dagger} p<0.05$, compared with $4 \mathrm{~h}$ post lipid administration; ${ }^{\star} p<0.05$, compared with 24 h post lipid administration

Between 6 and 12 weeks of age, intracellular lipid content in skeletal muscle decreased by $43 \%$ in $f a /+$ rats, whereas it increased by $73 \%$ in $f a / f a$ rats. These agedependent changes in IMCL content are in excellent agreement with our previous study in ZDF rats [40]. The decreased IMCL content in $f a /+$ rats at 12 weeks of age was accompanied by a $44 \%$ lower dietary lipid uptake at $4 \mathrm{~h}$ after administration compared with $f a /+$ rats at 6 weeks of age. In diabetic $f a / f a$ rats at 12 weeks, on the other hand, the increased IMCL content was associated with a $217 \%$ higher dietary lipid uptake at $4 \mathrm{~h}$ compared with prediabetic $f a / f a$ rats at 6 weeks of age. As a result, postprandial lipid uptake in muscle of diabetic rats was 3.4-fold higher when compared with controls, which is in accordance with previous reports of increased muscle lipid uptake in patients with type 2 diabetes during postprandial conditions $[6,9,12]$. In contrast, during postabsorptive conditions, muscle lipid uptake has generally been found to be decreased in type 2 diabetes patients $[9,22,23,25]$.

The elevated uptake of dietary lipids in diabetic muscle is in sharp contrast with the lower muscle lipid uptake in prediabetic rats when compared with insulin-sensitive controls. Our data on liver lipid uptake suggest that in diabetic rats the maximum lipid buffer capacity of the liver has been reached, which might expose skeletal muscle to greater 
plasma TAG and NEFA fluxes in the immediate postprandial period, leading to an increase in muscle lipid uptake. Alternatively, the increased postprandial muscle lipid uptake after the progression from prediabetes to overt type 2 diabetes could also be due to changes at the level of skeletal muscle itself. In type 2 diabetes, hyperinsulinaemia increases skeletal muscle lipoprotein lipase activity [43], which could lead to an increased fatty acid delivery to the diabetic muscle. Fatty acid transport into the myocyte is largely mediated by proteins, of which fatty acid translocase CD36 (FAT/CD36) plays a key role [44]. The increased fatty acid uptake in giant sarcolemmal vesicles from muscle of type 2 diabetic patients and obese Zucker rats could, however, not be explained by an increased production of FAT/ CD36 [7, 10]. Instead, the increase in fatty acid transport was associated with an increased abundance of FAT/CD36 at the plasma membrane [7, 10]. Our findings of reduced muscle lipid uptake in prediabetic rats and increased lipid uptake in muscle of rats with overt type 2 diabetes suggest that during the progression from prediabetes to diabetes, the expression and/or plasmalemmal content of FAT/CD36 has been increased. Indeed, in giant sarcolemmal vesicles from red muscle of ZDF rats there was a marked increase in both protein production and plasmalemmal content of FAT/CD36 between 6 and 12 weeks of age [45]. However, in white muscle this upregulation was completely absent [45]. Rat TA muscle is composed of a red region and a white region and the MRS voxel contained both red and white muscle. Therefore, while our results might not be universally true for all muscle types, they might be representative for mixed muscles, such as most human skeletal muscles.

In contrast to findings in healthy control rats, ${ }^{13} \mathrm{C}$-labelled IMCL in prediabetic and diabetic rats did not significantly decrease between 4 and $24 \mathrm{~h}$ after the administration of ${ }^{13} \mathrm{C}$-labelled lipids, indicating lower lipid oxidation. Daily activity levels are very similar in $f a /+$ and $f a l f a$ rats [46] and therefore the lower lipid turnover in $f a / f a$ rats is likely the result of an impairment in lipid oxidation. These results are in accordance with previous reports of reduced lipid oxidation in insulin-resistant and type 2 diabetic muscle $[9,17,18,20-25,29]$.

In conclusion, we have shown that in both prediabetic and diabetic rats, total lipid contents in skeletal muscle and liver are substantially higher than in healthy controls. In the liver, this is accompanied by a highly elevated in-vivo postprandial lipid uptake in both prediabetic and diabetic rats. In contrast, skeletal muscle of prediabetic rats is protected from excess lipid uptake and muscle lipid uptake is only elevated following the development of overt diabetes. Our data suggest that the accumulation of lipids in prediabetic muscle is mainly attributed to impaired lipid oxidation, whereas lipid uptake is strongly increased following the development of an overt type 2 diabetic state.
Acknowledgements The authors would like to acknowledge D. Veraart, L. Niesen, J. Habets and T. Geraedts (Biomedical NMR, Department of Biomedical Engineering, Eindhoven University of Technology, Eindhoven, the Netherlands) for technical assistance.

Funding J. J. Prompers is supported by a VIDI grant (project No. 700.58.421) from the Netherlands Organisation for Scientific Research (NWO).

Duality of interest The authors declare that there is no duality of interest associated with this manuscript.

Contribution statement All authors contributed to the study concept and design and the interpretation of the data. RAMJ and JJP acquired and analysed the data and drafted the manuscript. LJCvL and $\mathrm{KN}$ reviewed the manuscript for important intellectual content. All authors revised the article and approved the final version to be published.

Open Access This article is distributed under the terms of the Creative Commons Attribution Noncommercial License which permits any noncommercial use, distribution, and reproduction in any medium, provided the original author(s) and the source are credited.

\section{References}

1. Krssak M, Falk Petersen K, Dresner A et al (1999) Intramyocellular lipid concentrations are correlated with insulin sensitivity in humans: a ${ }^{1} \mathrm{H}$ NMR spectroscopy study. Diabetologia 42:113-116

2. Perseghin G, Scifo P, de Cobelli F et al (1999) Intramyocellular triglyceride content is a determinant of in vivo insulin resistance in humans: a ${ }^{1} \mathrm{H}^{13} \mathrm{C}$ nuclear magnetic resonance spectroscopy assessment in offspring of type 2 diabetic parents. Diabetes 48:1600-1606

3. Kelley DE, McKolanis TM, Hegazi RA, Kuller LH, Kalhan SC (2003) Fatty liver in type 2 diabetes mellitus: relation to regional adiposity, fatty acids, and insulin resistance. Am J Physiol Endocrinol Metab 285:E906-E916

4. Ryysy L, Hakkinen AM, Goto T et al (2000) Hepatic fat content and insulin action on free fatty acids and glucose metabolism rather than insulin absorption are associated with insulin requirements during insulin therapy in type 2 diabetic patients. Diabetes 49:749-758

5. Samuel VT, Petersen KF, Shulman GI (2010) Lipid-induced insulin resistance: unravelling the mechanism. Lancet 375:2267-2277

6. Bell JA, Volpi E, Fujita S, Cadenas JG, Rasmussen BB (2006) Dysregulation of muscle fatty acid metabolism in type 2 diabetes is independent of malonyl-CoA. Diabetologia 49:2144-2152

7. Bonen A, Parolin ML, Steinberg GR et al (2004) Triacylglycerol accumulation in human obesity and type 2 diabetes is associated with increased rates of skeletal muscle fatty acid transport and increased sarcolemmal FAT/CD36. FASEB J 18:1144-1146

8. Hegarty BD, Cooney GJ, Kraegen EW, Furler SM (2002) Increased efficiency of fatty acid uptake contributes to lipid accumulation in skeletal muscle of high fat-fed insulin-resistant rats. Diabetes 51:1477-1484

9. Kelley DE, Simoneau JA (1994) Impaired free fatty acid utilization by skeletal muscle in non-insulin-dependent diabetes mellitus. J Clin Invest 94:2349-2356

10. Luiken JJ, Arumugam Y, Dyck DJ et al (2001) Increased rates of fatty acid uptake and plasmalemmal fatty acid transporters in obese Zucker rats. J Biol Chem 276:40567-40573

11. Moors CC, van der Zijl NJ, Diamant M, Blaak EE, Goossens GH (2012) Impaired insulin sensitivity is accompanied by disturbances in skeletal muscle fatty acid handling in subjects with impaired glucose metabolism. Int J Obes (Lond) 36:709-717 
12. Ravikumar B, Carey PE, Snaar JE et al (2005) Real-time assessment of postprandial fat storage in liver and skeletal muscle in health and type 2 diabetes. Am J Physiol Endocrinol Metab 288: E789-E797

13. Steinberg GR, Parolin ML, Heigenhauser GJ, Dyck DJ (2002) Leptin increases FA oxidation in lean but not obese human skeletal muscle: evidence of peripheral leptin resistance. Am J Physiol Endocrinol Metab 283:E187-E192

14. Turcotte LP, Swenberger JR, Zavitz Tucker M, Yee AJ (2001) Increased fatty acid uptake and altered fatty acid metabolism in insulinresistant muscle of obese Zucker rats. Diabetes 50:1389-1396

15. van Hees AM, Jans A, Hul GB, Roche HM, Saris WH, Blaak EE (2011) Skeletal muscle fatty acid handling in insulin resistant men. Obesity 19:1350-1359

16. Capaldo B, Napoli R, Di Marino L, Picardi A, Riccardi G, Sacca L (1988) Quantitation of forearm glucose and free fatty acid (FFA) disposal in normal subjects and type II diabetic patients: evidence against an essential role for FFA in the pathogenesis of insulin resistance. J Clin Endocrinol Metab 67:893-898

17. Gaster M, Rustan AC, Aas V, Beck-Nielsen H (2004) Reduced lipid oxidation in skeletal muscle from type 2 diabetic subjects may be of genetic origin: evidence from cultured myotubes. Diabetes 53:542-548

18. Kelley DE, Goodpaster B, Wing RR, Simoneau JA (1999) Skeletal muscle fatty acid metabolism in association with insulin resistance, obesity, and weight loss. Am J Physiol 277:E1130-E1141

19. Labbe SM, Croteau E, Grenier-Larouche T et al (2011) Normal postprandial nonesterified fatty acid uptake in muscles despite increased circulating fatty acids in type 2 diabetes. Diabetes 60:408-415

20. Lopez-Soriano EJ, Carbo N, Argiles JM (1991) Lipid metabolism in the obese Zucker rat. Disposal of an oral [14C]triolein load and lipoprotein lipase activity. Biochem J 274:651-656

21. Bessesen DH, Rupp CL, Eckel RH (1995) Dietary fat is shunted away from oxidation, toward storage in obese Zucker rats. Obes Res 3:179-189

22. Blaak EE, Wagenmakers AJ (2002) The fate of [U-(13)C]palmitate extracted by skeletal muscle in subjects with type 2 diabetes and control subjects. Diabetes 51:784-789

23. Blaak EE, Wagenmakers AJ, Glatz JF et al (2000) Plasma FFA utilization and fatty acid-binding protein content are diminished in type 2 diabetic muscle. Am J Physiol Endocrinol Metab 279: E146-E154

24. Cha BS, Ciaraldi TP, Park KS, Carter L, Mudaliar SR, Henry RR (2005) Impaired fatty acid metabolism in type 2 diabetic skeletal muscle cells is reversed by PPARgamma agonists. Am J Physiol Endocrinol Metab 289:E151-E159

25. Mensink M, Blaak EE, van Baak MA, Wagenmakers AJ, Saris WH (2001) Plasma free fatty acid uptake and oxidation are already diminished in subjects at high risk for developing type 2 diabetes. Diabetes 50:2548-2554

26. Perreault L, Bergman BC, Hunerdosse DM, Eckel RH (2010) Altered intramuscular lipid metabolism relates to diminished insulin action in men, but not women, in progression to diabetes. Obesity 18:2093-2100

27. Turpeinen AK, Takala TO, Nuutila P et al (1999) Impaired free fatty acid uptake in skeletal muscle but not in myocardium in patients with impaired glucose tolerance: studies with PET and 14(R, S)-[18 F] fluoro-6-thia-heptadecanoic acid. Diabetes 48:1245-1250

28. Wilmsen HM, Ciaraldi TP, Carter L, Reehman N, Mudaliar SR, Henry RR (2003) Thiazolidinediones upregulate impaired fatty acid uptake in skeletal muscle of type 2 diabetic subjects. Am J Physiol Endocrinol Metab 285:E354-E362
29. Kim JY, Hickner RC, Cortright RL, Dohm GL, Houmard JA (2000) Lipid oxidation is reduced in obese human skeletal muscle. Am J Physiol Endocrinol Metab 279:E1039-E1044

30. Muurling M, van den Hoek AM, Mensink RP et al (2004) Overexpression of APOC1 in obob mice leads to hepatic steatosis and severe hepatic insulin resistance. J Lipid Res 45:9-16

31. Berk PD, Zhou SL, Kiang CL, Stump D, Bradbury M, Isola LM (1997) Uptake of long chain free fatty acids is selectively upregulated in adipocytes of Zucker rats with genetic obesity and non-insulin-dependent diabetes mellitus. J Biol Chem 272:8830 8835

32. Adiels M, Taskinen MR, Packard C et al (2006) Overproduction of large VLDL particles is driven by increased liver fat content in man. Diabetologia 49:755-765

33. Bourgeois CS, Wiggins D, Hems R, Gibbons GF (1995) VLDL output by hepatocytes from obese Zucker rats is resistant to the inhibitory effect of insulin. Am J Physiol Endocrinol Metab 269: E208-E215

34. Cohn JS, Patterson BW, Uffelman KD, Davignon J, Steiner G (2004) Rate of production of plasma and very-low-density lipoprotein (VLDL) apolipoprotein C-III is strongly related to the concentration and level of production of VLDL triglyceride in male subjects with different body weights and levels of insulin sensitivity. J Clin Endocrinol Metab 89:3949-3955

35. Jonkers RA, Geraedts TR, van Loon LJ, Nicolay K, Prompers JJ (2012) Multitissue assessment of in vivo postprandial intracellular lipid partitioning in rats using localized ${ }^{1} \mathrm{H}-\left[{ }^{13} \mathrm{C}\right]$ magnetic resonance spectroscopy. Magn Reson Med 68:997-1006

36. Clark JB, Palmer CJ, Shaw WN (1983) The diabetic Zucker fatty rat. Proc Soc Exp Biol Med 173:68-75

37. Etgen GJ, Oldham BA (2000) Profiling of Zucker diabetic fatty rats in their progression to the overt diabetic state. Metabolism 49:684-688

38. Vanhamme L, van den Boogaart A, van Huffel S (1997) Improved method for accurate and efficient quantification of MRS data with use of prior knowledge. J Magn Reson 129:35-43

39. De Feyter HM, Schaart G, Hesselink MK, Schrauwen P, Nicolay K, Prompers JJ (2006) Regional variations in intramyocellular lipid concentration correlate with muscle fiber type distribution in rat tibialis anterior muscle. Magn Reson Med 56:19-25

40. De Feyter HM, Lenaers E, Houten SM et al (2008) Increased intramyocellular lipid content but normal skeletal muscle mitochondrial oxidative capacity throughout the pathogenesis of type 2 diabetes. FASEB J 22:3947-3955

41. Frayn KN (2002) Adipose tissue as a buffer for daily lipid flux. Diabetologia 45:1201-1210

42. Lambert JE, Parks EJ (2012) Postprandial metabolism of meal triglyceride in humans. Biochim Biophys Acta 1821:721-726

43. Yost TJ, Froyd KK, Jensen DR, Eckel RH (1995) Change in skeletal muscle lipoprotein lipase activity in response to insulin/ glucose in non-insulin-dependent diabetes mellitus. Metabolism 44:786-790

44. Bonen A, Campbell SE, Benton CR et al (2004) Regulation of fatty acid transport by fatty acid translocase/CD36. Proc Nutr Soc $63: 245-249$

45. Chabowski A, Chatham JC, Tandon NN et al (2006) Fatty acid transport and FAT/CD36 are increased in red but not in white skeletal muscle of ZDF rats. Am J Physiol Endocrinol Metab 291:E675-E682

46. Keesey RE, Swiergiel AH, Corbett SW (1990) Contribution of spontaneous activity to daily energy expenditure of adult obese and lean Zucker rats. Physiol Behav 48:327-331 